\title{
Modeling Twitter Acceptance and Use under the Risk of Antisocial Behavior
}

\author{
Nora AlMuhanna ${ }^{1}, 2$, Wendy Hall ${ }^{1}$, and David E. Millard ${ }^{1}$ \\ Web and Internet Science Group \\ Electronics and Computer Science \\ ${ }^{1}$ University of Southampton, Southampton, UK \\ ${ }^{2}$ King Saud University, Riyadh, Saudi Arabia \\ \{na8g14, wh, dem\}@ecs.soton.ac.uk
}

\begin{abstract}
The problem of online antisocial behavior is increasingly attracting public attention and is compromising the quality of online communities. Previous research on online hostility looked at different aspects of the problem such as its definition, classification, or studying specific case studies, however, the impact is still not clear. In this paper, we propose a new model to investigate the impact of antisocial behavior online, the model is based on the Unified Theory of Acceptance and Use of Technology (UTAUT), our model integrates the perception of antisocial behavior as a risk factor along with other factors drawn from sociology. Initial validation of our model was conducted through expert reviews, the reviews include interviews with experts from computer science, sociology, and psychology, who were asked to consider its application to Twitter (as one of the controversial cyberspaces when it comes to antisocial behavior). The results of both quantitative and qualitative analysis of the expert reviews show strong support to the proposed model.
\end{abstract}

\section{CCS Concepts}

- Information systems $\rightarrow$ World Wide Web $\rightarrow$ social networks.

\section{Keywords}

Antisocial behavior; social network; user behavior; Twitter; technology acceptance and use; UTAUT; self-presentation.

\section{INTRODUCTION}

The Web is one of the significant advances in the twentieth century, from its origins as a web of documents, it has evolved into a unique ecosystem encompassing technology and people. Millions of people are now using social network sites to communicate on daily basis, they have been utilized for many purposes, but regardless the huge benefit that SNS bring, people sometimes show disturbing behavior online. Web Science posits that it is crucial to understand the interaction between people and technology online, as through this understanding we can get insights that help in building better systems, and addressing problems such as anti-social behavior [1].

Early works on computer mediated communication studied the effect of the medium on humans' communication and developed many theories explaining that effect and interaction [2]. However, the effect of antisocial behavior online remains unclear. Moreover, to the best of our knowledge, online hostility was entirely neglected in the literature of user acceptance and use of technology for online communities. Some previous studies on technology acceptance have considered economic related risk factors in internet banking or on e-services where users purchase items online [3]. In addition,

Permission to make digital or hard copies of part or all of this work for personal or classroom use is granted without fee provided that copies are not made or distributed for profit or commercial advantage and that copies bear this notice and the full citation on the first page. Copyrights for third-party components of this work must be honored. For all other uses, contact the Owner/Author. Copyright is held by the owner/author(s).

WebSci '16, May 22-25, 2016, Hannover, Germany.

ACM 978-1-4503-4208-7/16/05.

http://dx.doi.org/10.1145/2908131.2908182 a recent systematic literature review of 38 studies from 2002 until 2014 discussed empirical studies on online community participation and highlighted that in the context of their review, no research was conducted on online antisocial behavior and therefore, it is possible that some kinds of active participation might even be destructive [4]. The resilience of online communities and how users cope with online systems given the risks that they may face remains unclear. And to understand how online antisocial behavior affects online communities in a larger scale we propose to extend UTAUT [5], For the purpose of our study, Twitter is chosen as a target cyberspace as one of the controversial platforms with trolling [6].

\section{PROPOSED MODEL}

We propose to extend UTAUT, as it provides an effective model since it has been constructed by combining and testing pervious prominent models and theories from different disciplines. Moreover, most previous studies have confirmed the relationship between the constructs of the model and users' acceptance and use of technology (e.g. [7]). However, the model does not take into consideration any other 'risk' or negative factors that could affect the usage of technology, specifically, the perception of antisocial behavior risk. Therefore, our extension to the model aims to fill this gap by adding three additional factors. Crucially, the perceived risk of antisocial behavior, and then two supporting constructs, which are protective self-presentation awareness, and self-presentation objective Self-presentation objective refers to the extent to which individual control how he or she is perceived by others by carefully providing information to enhance his or her desired image on Twitter. Self-presentation is an important online behavior on social networks [7, 19]. Protective self-presentation awareness refers to the extent to which an individual is aware about the strategies which are performed to overcome or minimize the impact of antisocial behavior on one's image [8]. Previous studies revealed that the perception of antisocial behavior (PAB) made users refrain from participating in online communities [9], [10]. Thus, we include it as a moderating factor on the model to find how it will affect the other factors. The model is shown on Fig. 1 with our extensions depicted using dashed lines. Table 1 summarizes the factors and the sub-factors. The main factors are defined as follows:

1. Performance Expectancy: the degree to which an individual believes that using Twitter is useful in his or her different tasks including work, socializing, or other different goals.

2. Effort Expectancy: the degree of ease associated with Twitter use. This factor is described in terms of tow sub-factors.

3. Social Influence: the degree to which individual perceived that others approved of his or her participation on Twitter.

4. Facilitating Conditions: the degree to which an individual believes that there is organizational, technical, and personal support and control over Twitter use. 


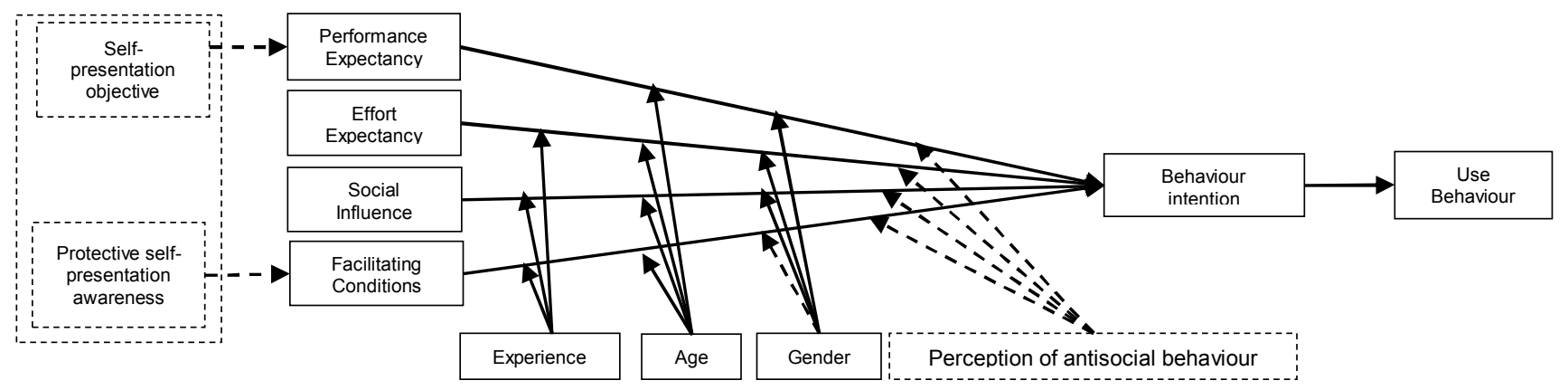

Figure 1. Initial Proposed Model.

\begin{tabular}{|l|l|}
\hline \multicolumn{1}{|c|}{ Factor } & \multicolumn{1}{c|}{ Sub-factor } \\
\hline \multirow{3}{*}{$\begin{array}{l}\text { Performance } \\
\text { expectancy (PE) }\end{array}$} & Perceived usefulness [17], [18]. \\
\cline { 2 - 2 } & Outcome expectation [5]. \\
\cline { 2 - 2 } $\begin{array}{l}\text { Effort Expectancy } \\
\text { (EE) }\end{array}$ & Self-presentation objective [7, 19, 20]. \\
\cline { 2 - 2 } Social Influence (SI) & Enjoyment [11], [12]. \\
\cline { 2 - 2 } & Subjective norm [5]. \\
\cline { 2 - 2 } $\begin{array}{l}\text { Facilitating } \\
\text { Conditions (FC) }\end{array}$ & Pommunity identification [13]. \\
\cline { 2 - 2 } & Perceived behavioural control [5]. \\
\cline { 2 - 2 } & Protective self-presentation awareness [8]. \\
\hline
\end{tabular}

Table 1. Main factors and sub-factors in the proposed model.

\section{Methodology}

This work follows a mixed research method in which we try to triangulate different data to gain better understanding. As we have drawn out our model from the literature, a validation step is essential, and expert reviews where conducted to validate the model. The expert reviews were designed as semi-structured interviews in which closed ended questions were presented on a questionnaire covering each component in the model. Open ended questions regarding the newly added components were also presented. The sample size was 12 experts who have published or worked on the model or in a similar area, they include 9 computer scientists, 2 sociologists, and a psychologist. Each interview took about one hour, first, the experts were given a brief summary and the model in Fig. 1 was completely explained and they were allowed to ask questions. Second, they were given the questionnaire and they were asked to rate each statement on a 5-point Likert. After that, they were asked the open ended questions about the newly added components followed by a general discussion.

\section{RESULTS AND DISCUSSION}

Experts' response were analyzed using One Sample T-test. The hypothesized mean was set to 3 , which corresponds to Neutral in the Likert scale. The statistical significance level alpha was set to 0.01 . Tables 1 and 2 show the results including the mean and the p-value. Most components had mean values greater than 3 and were significant, only two components had mean values less than 3 .

As for the qualitative analysis, experts were asked questions about each new factor, whether they agree with it and think it is important in the context of the research, and whether it fits in the model. The discussion with the experts revealed high agreement with the proposed model. Generally they agreed with all factors, except perceived behavioral control and facilitating conditions as they thought they will not be important in case of Twitter. Experts expressed strong support with including self-presentation objective and protective self-presentation awareness in the model, an example from an interview:
Expert F: "for example we did the gamer gate talk here a while ago, and I was tweeting about it but I didn't mention the word 'gamergate' because it then would be showed on other people's feed and then they would tweet at me."

Interviewer: "So your awareness about it made you act differently? Expert F: "Yes, because of my perception of antisocial behavior I changed the way I behaved."

The perception of antisocial behavior was also strongly supported by the experts, one said "Trolling online is huge, it definitely changes the way people interact, I imaging the knowledge of it leads to selfcensorship". But, some experts advised that it should be considered as a main factor. Experts split on gender as technical experts thought it will not be important whereas social scientist thought it is a key moderator, therefor we plan to investigate its effect.

\begin{tabular}{|l|c|c|c|c|}
\cline { 2 - 6 } \multicolumn{1}{c|}{ Moderator } & PE & EE & SI & FC \\
\hline Experience & & $4.58[.000]$ & $4.17[.000]$ & $4.25[.000]$ \\
\hline Age & $3.83[.005]$ & $4.17[.000]$ & $4.17[.000]$ & $4.00[.000]$ \\
\hline Gender & $2.67[.220]$ & $2.67[.104]$ & $3.58[.046]$ & $3.58[.046]$ \\
\hline PAB & $4.25[.000]$ & $4.42[.000]$ & $4.33[.000]$ & $4.25[.000]$ \\
\hline \multicolumn{5}{|c|}{ Legend: Mean [p-value] } \\
\hline
\end{tabular}

Table 2. T-test result for the moderator/factor relationship.

\begin{tabular}{|l|l|l|l|}
\hline Factor & \multicolumn{1}{|c|}{ Sub-factor } & Mean & p-value \\
\hline \multirow{3}{*}{$\begin{array}{l}\text { Performance } \\
\text { expectancy (PE) }\end{array}$} & Perceived usefulness & 4.00 & .002 \\
\cline { 2 - 4 } & Outcome expectation & 4.25 & .000 \\
\cline { 2 - 4 } & Self-presentation objective & 4.42 & .000 \\
\hline \multirow{2}{*}{$\begin{array}{l}\text { Effort } \\
\text { Expectancy (EE) }\end{array}$} & Perceived ease of use & 4.25 & .001 \\
\cline { 2 - 4 } & Enjoyment & 4.08 & .000 \\
\hline \multirow{2}{*}{$\begin{array}{l}\text { Social Influence } \\
\text { (SI) }\end{array}$} & Subjective norm & 3.83 & .000 \\
\cline { 2 - 4 } & Community identification & 3.75 & .005 \\
\hline \multirow{3}{*}{$\begin{array}{l}\text { Facilitating } \\
\text { Conditions (FC) }\end{array}$} & Perceived behavioural control & 3.42 & $\mathbf{. 0 9 6}$ \\
\cline { 2 - 4 } & Facilitating conditions & 3.42 &. $\mathbf{1 3 7}$ \\
\cline { 2 - 4 } & Protective self-presentation awareness & 3.83 & .002 \\
\hline
\end{tabular}

Table 3. T-test result for the factors

\section{CONCLUSION AND FUTURE WORK}

This paper proposed a new model to investigate the problem of the perception of antisocial behavior on Twitter use. The model extends the UTAUT by adding perception of antisocial behavior as a risk factor. It also integrates self-presentation objective and protective self-presentation awareness to allow for a wider understanding of users' resilience on using Twitter given the existence of that perceived risk. Expert reviews were conducted as an initial validation step of the model. Results showed strong support for the model and in our future work we intend to use it as the theoretical basis for an online questionnaire to study the relative importance of its various constructs for users of the Twitter social networking system. 


\section{REFERENCES}

[1] T. Berners-Lee, D. J. Weitzner, W. Hall, K. O'Hara, N. Shadbolt, and J. A. Hendler, "A Framework for Web Science," Found. Trends ${ }^{\circledR}$ Web Sci., vol. 1, no. 1, pp. 1130, Jan. 2006.

[2] G. Bubaš, "Computer mediated communication theories and phenomena: Factors that influence collaboration over the internet," 3rd CARNet users Conf. Zagreb. Hungary, no. CMC, 2001.

[3] C. Martins, T. Oliveira, and A. Popovič, "Understanding the Internet banking adoption: A unified theory of acceptance and use of technology and perceived risk application," Int. J. Inf. Manage., vol. 34, no. 1, pp. 1-13, 2014.

[4] S. Malinen, "Understanding user participation in online communities: A systematic literature review of empirical studies," Comput. Human Behav., vol. 46, pp. 228-238, 2015.

[5] F. D. D. Viswanath Venkatesh, Michael G Morris, Gordon B Davis, "User Acceptance of Information Technology: Toward A Unified View," MIS Q., vol. 27, no. 3, pp. 425-478, 2003.

[6] A. Younus, M. A. Qureshi, M. Saeed, N. Touheed, C. O’Riordan, and G. Pasi, "Election Trolling: Analyzing Sentiment in Tweets During Pakistan Elections 2013," Proc. Companion Publ. 23rd Int. Conf. World Wide Web Companion, pp. 411-412, 2014.
[7] T. Sundaravej, "Empirical validation of unified theory of acceptance and use of technology model," J. Glob. Inf. Technol. Manag., vol. 13, no. 1, pp. 5-27, 2010.

[8] J. Rui and M. Stefanone, "Strategic image management online: Self-presentation, self-esteem and social network perspectives," Information, Commun. Soc., vol. 16, no. 8, pp. 1286-1305, 2013.

[9] P. G. Lange, "Searching for the 'You' in 'YouTube': An Analysis of Online Response Ability," Ethnogr. Prax. Ind. Conf. Proc., vol. 2007, no. 1, pp. 36-50, Oct. 2007.

[10] P. J. Moor, A. Heuvelman, and R. Verleur, "Flaming on YouTube," Comput. Human Behav., vol. 26, no. 6, pp. 1536-1546, 2010.

[11] C. L. Hsu and J. C. C. Lin, “Acceptance of blog usage: The roles of technology acceptance, social influence and knowledge sharing motivation," Inf. Manag., vol. 45, pp. 65-74, 2008.

[12] S. Black, "Working Papers on Information Systems Twitter Acceptance : The Role of Intrinsic Motivation Twitter acceptance : the role of intrinsic motivation," Proc. ALPIS. Sprouts Work. Pap. Inf. Syst. 10(9)., vol. 10, no. 2010, 2010.

[13] A. Hars and S. Ou, "Working for free? Motivations of participating in open source projects," in System Sciences, the 34th Annual Hawaii International Conference, 2001. 